\section{Comparative evalua- tion of propofol and thiopentone for total intravenous anaesthesia}

Hillel Kashtan MD FRCPC, Gerald Edelist MD FRCPC, Joseph Mallon MD FRCPC, Deena Kapala RN
Sixty unpremedicated ASA physical status I or II patients scheduled for surgical procedures of intermediate duration (15 to $60 \mathrm{~min}$ ) were studied to evaluate the safery and efficacy of propofol, to measure recovery times and to compare the return of psychomotor and cognitive function with thiopentone. $\mathrm{Pa}$ tients were randomly allocated into two groups. Anaesthesia was induced and maintained by either propofol (2.0-2.5 $\mathrm{mg} \cdot \mathrm{kg}^{-1}$ followed by a continuous infusion $0.1-0.2 \mathrm{mg}$. $\left.\mathrm{kg}^{-1} \cdot \mathrm{min}^{-1}\right)$ or thiopentone $\left(4.0-5.0 \mathrm{mg} \cdot \mathrm{kg}^{-1}\right.$, and infusion rate $\left.0.16-0.32 \mathrm{mg} \cdot \mathrm{kg}^{-1} \cdot \mathrm{min}^{-1}\right)$, titrated to patient response. Succinylcholine was administered to facilitate tracheal intubation and maintain neuromuscular blockade. Induction of anaesthesia was slightly longer with propofol than thiopentone 142.2 vs $29.8 \mathrm{sec}$ ) and was smooth with both drugs. Post-intubation increases in heart rate, and systolic and diastolic blood pressures were attenuated by propofol when compared with thiopentone. After the administration of propofol, times to eye opening $(6.4 \pm 4.3$ vs $13.9 \pm 15.9 \mathrm{~min})$, response to verbal command ( $7.6 \pm 6.3$ vs $15.4 \pm 16.6 \mathrm{~min})$ and orientation $(22.7$ \pm 12.8 vs $36.2 \pm 23.1 \mathrm{~min})$, were significantly shorter. Psychomotor and cognitive function returned earlier with propofol and fewer side effects were noted. At $24 \mathrm{hr}$ there was no distinguishable difference between groups. Propofol is a safe anaesthetic agent with the potential for early patient discharge and street fitness after outpatient procedures.

Dans un effort pour établir la sûreté et l'efficacité du propofol, et pour en comparer les délais d'éveil et les effets sur la

\section{Key words}

ANAESTHETIC TECHNIQUES: intravenous, total; ANAESTHETICS, INTRAVENOUS: propofol, thiopentone; RECOVERY: assessments, cognitive function, psychomotor function.

From the Department of Anaesthesia, Mount Sinai Hospital, University of Toronto, 600 University Avenue, Toronto, Ontario, M5G IX5.

Address correspondence to: Dr. G. Edelist.

This study was supported by a grant from ICI Pharmaceuticals of Canada. psychomotricité et sur les fonctions cognitives avec ceux du thiopental, nous avons conduit une étude prospective chez 60 patients randomisés de classe ASA I ou II lors d'interventions d'une durée de 15 à 60 minutes. Les patients recevaient soit du propofol (2,0-2,5 $\mathrm{mg} \cdot \mathrm{kg}^{-1}$ suivi d' une infusion a $0,1-0,2 \mathrm{mg}$. $\left.\mathrm{kg}^{-1} \cdot \mathrm{min}^{-1}\right)$, soit du thiopental $\left(4,0-5,0 \mathrm{mg} \cdot \mathrm{kg}^{-1}\right.$, infusion de $0,16-0,32 \mathrm{mg} \cdot \mathrm{kg}^{-1} \cdot \mathrm{min}^{-1}$ ) ajustés selon la réponse. On se servait de succinylcholine pour l'intubation de la trachée et pour maintenir le relâchement musculaire. L'induction de l'anesthésie s'est faite en douceur avec les deux anesthésiques quoique un peu plus lentement avec le propofol $(42,2$ vs 29,8 sec). L'augmentation du pouls et des pressions artérielles systolique et diastolique lors de l'intubation, était moins marquée avec le propofol qu' avec le thiopental. Les délais entre la fin de l' infusion et l' ouverture des yeux $(6,4 \pm 4,3$ vs $13,9 \pm$ $15,9 \mathrm{~min})$, la réponse aux ordres verbaux $(7,6 \pm 6,3$ vs $15,4 \pm$ $16,6 \mathrm{~min})$ et le retour de l'orientation $(22,7 \pm 12,8 \mathrm{vs} 36,2 \pm$ 23,1 min) étaient plus courts avec le propofol qu'avec le thiopental. Après une anesthésie au propofol, la récupération des fonctions psychomotrices et cognitives survenait plus rapidement avec moins d'effets secondaires quoique d̀ 24 heures, les deux groupes soient indifférenciables. Lors de chirurgie en externe, le propofol est un anesthésique sûr permettant de donner congé précocément à des patients alertes.

Anaesthetic agents must provide not only optimal operating conditions but also rapid recovery after surgery. The pharmacokinetic properties of propofol (2.6 diisopropylphenol), a new intravenous hypnotic agent, suggest that it should allow rapid return of psychomotor function, with a potential for early discharge and street fitness after outpatient procedures. Previous studies utilizing various methods of recovery suggest that propofol compares favourably with other anaesthetic agents. ${ }^{1-3}$ There still remains the need to define more precisely the early and late recovery characteristics of this new induction agent.

The objectives of this study were to evaluate the safety and efficacy of propofol for the induction and maintenance of general anaesthesia for procedures of intermediate duration, to evaluate specific recovery times and to assess the effects of propofol versus thiopentone on 
recovery of cognitive function and psychomotor performance.

\section{Methods}

Sixty adult patients, ASA physical status I and II, scheduled for elective operative procedures of anticipated intermediate duration (15-60 $\mathrm{min}$ ) were studied. The protocol was approved by the Human Subjects Review Committee of the University of Toronto and written informed consent was obtained prior to participation. Criteria for exclusion from the study included age less than 18 or greater than 70 years, previous adverse experience with general/intravenous anaesthesia, history of allergy to the trial drugs and their constituents, an inability to communicate effectively with the investigator or evidence of significant hepatic, renal, cardiorespiratory, haematological or metabolic disease. All premenopausal females had negative pregnancy tests prior to inclusion.

Eligible subjects were randomly assigned, by computer, into propofol $(n=30)$ and thiopentone $(n=30)$ groups. No patient received narcotic or sedative premedication. On the morning of surgery, baseline measurements of the following psychomotor tests were obtained: (1) deletion of P's; (2) Trieger dot; (3) visual analogue questionnaire of symptoms, plus a Romberg test and heel-toe walking assessment. All syringes and tubing were taped with non-transparent tape, and perioperative data were recorded by a research assistant who was blinded to the administered IV agent. Upon arrival in the operating room, an IV infusion of five per cent dextrose in lactated Ringer's was started. Monitoring devices applied were: automated blood pressure (Datascope accutor 2A), electrocardiogram (lead II), peripheral nerve stimulator and pulse oximeter. Baseline measurements of blood pressure, heart rate and oxygen saturation were recorded.

The induction sequence consisted of d-tubocurarine $3-4.5 \mathrm{mg}$ and fentanyl $1.5 \mu \mathrm{g} \cdot \mathrm{kg}^{-1}$ followed in one to three minutes by either propofol (one per cent solution) $2.0-2.5 \mathrm{mg} \cdot \mathrm{kg}^{-1}$ or thiopentone (2.5 per cent) $4.0-5.0$ $\mathrm{mg} \cdot \mathrm{kg}^{-1}$ injected over $20-30 \mathrm{sec}$. Patients were instructed to count slowly from the onset of trial drug injection. Induction time was determined as the number of seconds to cessation of counting. After the loss of lid reflex, succinylcholine $1.5 \mathrm{mg} \cdot \mathrm{kg}^{-1}$ was administered to facilitate tracheal intubation. Maintenance of anaesthesia was initiated immediately after completion of the induction sequence by a continuous infusion of propofol $0.1-0.2$ $\mathrm{mg} \cdot \mathrm{kg}^{-1} \cdot \mathrm{min}^{-1}$ or thiopentone $0.16-0.32 \mathrm{mg} \cdot \mathrm{kg}^{-1}$. $\mathrm{min}^{-1}$, titrated to patient response. The lungs were ventilated with 100 per cent oxygen (or 50 per cent $\mathrm{O}_{2} / \mathrm{N}_{2}$ during laser laryngoscopy). Neuromuscular blockade was provided by a 0.2 per cent succinylcholine infusion. Signs of light anaesthesia were treated with a 1-2 $\mathrm{ml}$ bolus of the appropriate study drug - propofol $10-20 \mathrm{mg}$ or thiopentone $25-50 \mathrm{mg}$. Heart rate, blood pressure (systolic, diastolic, mean) and oxygen saturation were recorded every minute for three minutes then every five minutes until the completion of surgery. In addition, these variables were measured immediately after tracheal intubation, surgical incision, termination of surgery, and extubation. Excitatory side effects or other responses were also noted. Upon completion of surgery, all infusions were discontinued (time $=0$ ). Recovery evaluations included time to spontaneous eye opening, response to verbal command and orientation to name, place and date of birth. The times at which individuals were able to tolerate clear fluids, void, sit and stand independently were recorded. Vital signs, adverse side effects and Aldrete scores were measured every $15 \mathrm{~min}$ from the time of PARR entry until discharge. In the recovery room, as soon as the patient was oriented and capable of sitting independently, psychometric Trieger dot and deletion of $P$ tests were performed. These were repeated every 30 min until transfer to the ward. If the patient's medical status permitted, a Romberg test was performed, and if negative, a walking test (heel-toe) was conducted. Prior to PARR discharge, patients were directly questioned regarding the presence of intraoperative awareness. A follow-up visit was initiated at $24 \mathrm{hr}$ to determine adverse symptoms as assessed by visual analogue scale, as well as the presence of recall and satisfaction with the anaesthetic technique.

All data are presented as proportions or as mean values \pm standard deviation. Statistical analysis of haemodynamic, induction and recovery time means was performed by unpaired 2-tailed $t$ tests. Psychometric Trieger dot and deletion of $P$ tests were analyzed using paired and unpaired $t$ tests. Differences in proportions were analysed by a chi-squared test with continuity correction. Statistical significance was accepted for $P<0.05$.

\section{Results}

Demographic data are presented in Table I. Both groups

TABLE I Demographic data

\begin{tabular}{lll}
\hline & Propofol $(n=30)$ & Thiopentone $(n=30)$ \\
\hline Age (Years) & $32.6 \pm 7.0$ & $36.7 \pm 9.0$ \\
Sex (F/M) & $27 / 3$ & $28 / 2$ \\
Weight (Kg) & $63.3 \pm 15.4$ & $63.0 \pm 13.2$ \\
ASA Status (III) & $29 / 1$ & $24 / 6$ \\
Surgical procedure: & & \\
$\quad$ Laparoscopy & 22 & 23 \\
$\quad$ Laser laryngoscopy & 6 & 6 \\
Arthroscopy & 2 & 1 \\
\hline
\end{tabular}


TABLE II Induction/maintenance dosages and times

\begin{tabular}{lcc}
\hline & Propofol & Thiopentone \\
\hline Induction dose $\left(\mathrm{mg} \cdot \mathrm{kg}^{-1}\right)$ & $2.18 \pm 0.37$ & $4.81 \pm 0.43$ \\
Cessation of counting $(\mathrm{sec})$ & $42.2 \pm 27.1$ & $29.8 \pm 6.1^{*}$ \\
Loss of lid reflex $(\mathrm{sec})$ & $48.6 \pm 29.6$ & $37.3 \pm 8.0 \dagger$ \\
Total dosage administered $\left(\mathrm{mg} \cdot \mathrm{kg}^{-1}\right)$ & $6.2 \pm 2.5$ & $12.8 \pm 4.0$ \\
Duration of anaesthesia (min) & $25.3 \pm 16.5$ & $24.1 \pm 12.0$ \\
\hline
\end{tabular}

$* P<0.02$.

$\dagger P<0.05$.

were comparable with respect to age, sex, weight, duration and type of surgical procedure. All patients in both groups lost consciousness with the administered induction dose. The mean induction time (Table II) was greater for propofol, $42.2 \mathrm{sec}$ versus $29.8 \mathrm{sec}$ in the thiopentone group $(P<0.02)$. Time to loss of lid reflex was also significantly prolonged with the administration of propofol. The total doses injected during induction were $139 \pm 31 \mathrm{mg}$ for propofol and $304 \pm 75$ for thiopentone. No patient in either group exhibited excitatory side effects (involuntary movement, hiccoughs, sneezing) during the induction of anaesthesia. Pain on injection was noted in three subjects (two propofol, one thiopentone). Another 11 patients given propofol complained of slight burning at the intravenous site.

Supplemental boluses were injected to treat signs of light anaesthesia in 20 per cent of patients in the propofol group compared with 6.7 per cent with thiopentone $(P>$ 0.10 ). In no case were more than two extra boluses necessary. The total dosages received intraoperatively were $6.2 \pm 2.5 \mathrm{mg} \cdot \mathrm{kg}^{-1}$ and $12.8 \pm 4.0 \mathrm{mg} \cdot \mathrm{kg}^{-1}$ for propofol and thiopentone, respectively.

Figure 1 illustrates the haemodynamic changes during the induction and maintenance of anaesthesia. Peak heart rates and blood pressures were observed, in all cases, approximately one to three minutes after intubation. These increases observed in both groups (in HR, systolic and diastolic blood pressures) were significantly less with propofol. Mean intraoperative heart rates were also significantly lower with propofol at 15 and $30 \mathrm{~min}$, and postextubation. Dysrhythmias occurred after laryngoscopy and intubation in three patients receiving thiopentone (unifocal VPB's $\times 2$, transient heart block $\times 1$ ).

The mean times to awakening after discontinuing the infusions were $6.4 \pm 4.3 \mathrm{~min}$ and $13.9 \pm 15.9 \mathrm{~min}$ for propofol and thiopentone, respectively. Statistical significance was also achieved when times to eye opening, orientation and response to verbal command were compared (Table III). Three individuals in the thiopentone group demonstrated a markedly prolonged recovery, i.e., time to eye opening $>30 \mathrm{~min}$. One of these subjects did not open her eyes until $82 \mathrm{~min}$ had elapsed after the
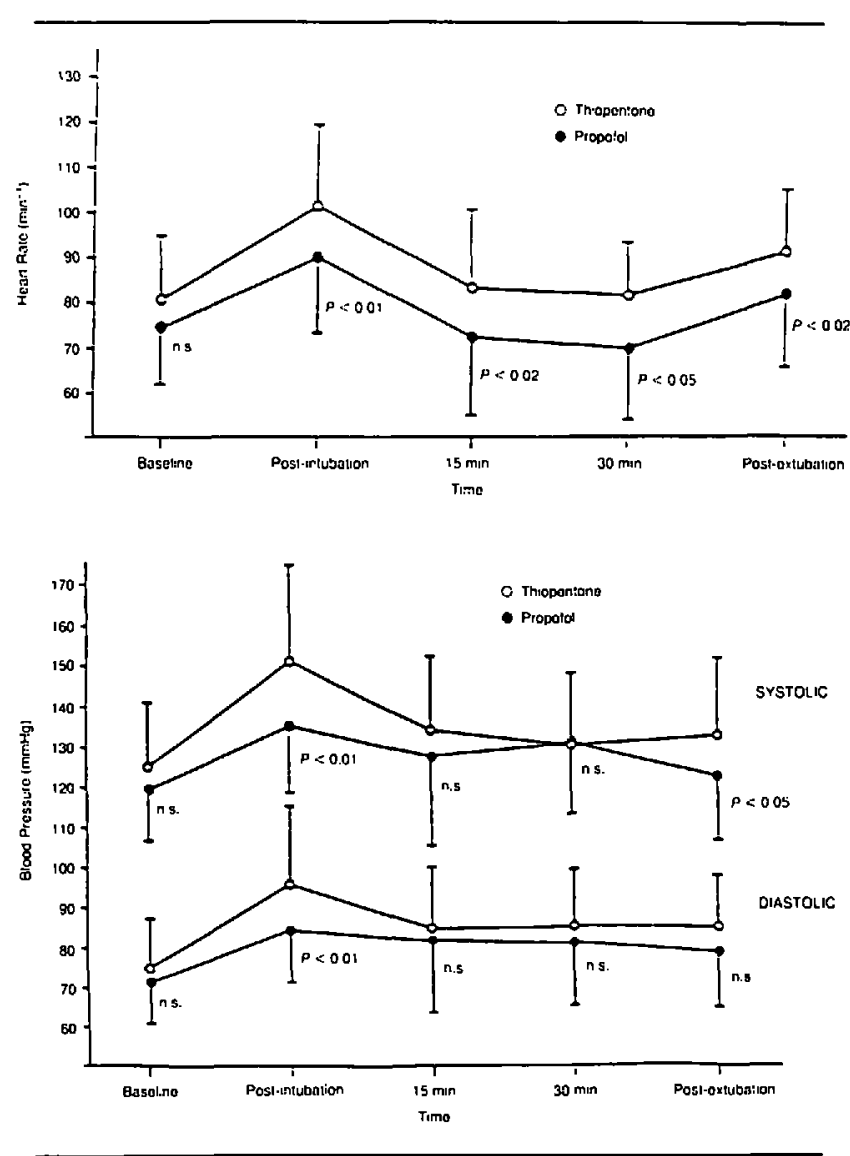

FIGURE 1 Perioperative haemodynamics.

infusion was discontinued. With the exclusion of these patients, recovery times were still significantly shorter with propofol. In the recovery room there was no statistical difference between groups in the number of patients administered either narcotics or gravol IM.

Dizziness sufficient to prevent standing was present in the immediate postoperative period in 53 per cent of the thiopentone group versus 13 per cent with propofol (Figure 2). A higher incidence of nausea and vomiting with thiopentone was not statistically significant. One subject in the propofol group exhibited emotional lability on emergence. Overall, only 26.7 per cent of patients administered thiopentone were free of adverse side effects compared with 66.7 per cent with propofol. Intraoperative awareness occurred in one subject given thiopentone.

Patients in the propofol group achieved an Aldrete score of ten, $22.6 \mathrm{~min}$ sooner than those given thiopentone $(P<0.001)$. The times required to tolerate fluids and sit independently were not significantly different. Prior to PARR discharge, seven propofol and 13 thiopentone patients were unable to stand. Of the remaining subjects, four in the propofol group had a negative Romberg test but could not walk. When thiopentone had been utilized, a further nine patients were unable to ambulate. 


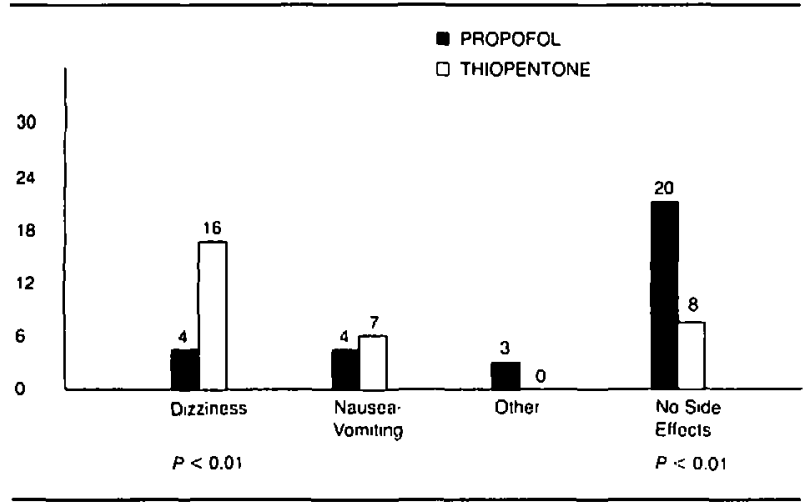

FIGURE 2 Adverse effects in recovery room.

Psychometric test results are displayed in Table IV. The Treiger dot test was scored according to the number of points missed (minimum 0 , maximum 42). No patient's score had returned to baseline values prior to recovery room discharge, although patients administered propofol omitted a significantly lower percentage of dots. The ability to delete P's had recovered to baseline values in both groups prior to their transfer to the ward. Postoperative adverse symptoms, assessed by a visual analogue questionnaire (Figure 3), indicated that by $24 \mathrm{hr}$ there was no difference in 14 of the 15 symptoms. The only exception was a subjective decreased ability of the thiopentone patients to concentrate. Both groups displayed a general feeling of weakness greater than baseline.

\section{Discussion}

Propofol (2.6 diisopropyl phenol), a new intravenous hypnotic agent, undergoes rapid redistribution, metabolism to inactive metabolites, and has a short elimination half life. ${ }^{4-6}$ These pharmacokinetic characteristics make this a favourable agent for outpatient anaesthesia by allowing rapid recovery of psychomotor and cognitive function.' In this study, which employed total intravenous anaesthesia, propofol was compared with equipotent doses of thiopentone for procedures of intermediate duration. ${ }^{7}$
Our study was conducted in a double-blind fashion. Most investigations to date have not been blinded due to the unique milky appearance of the propofol emulsion allowing easy identification. ${ }^{2-3,8-10}$ By wrapping all syringes and tubing with adiaphenous tape both patient and observer bias were eliminated although the potential for bias by the anaesthetist could not be completely removed.

Induction and maintenance of anaesthesia were easily achieved with both agents with few intraoperative problems. The infusion rate of propofol $\left(0.1-0.2 \mathrm{mg} \cdot \mathrm{kg}^{-1}\right.$. $\min ^{-1}$ ) has been shown to be effective for anaesthetic maintenance in surgical procedures of various durations. ${ }^{10-12.23-24}$ The only supplemental agent administered was a small dose of intravenous fentanyl prior to induction of anaesthesia. During the postoperative period, parenteral narcotics were given until adequate analgesia was obtained. With respect to the degree of pain, patients undergoing arthroscopy required the most narcotics and those undergoing laser laryngoscopy the least. A review of the demographic data indicates that the number of subjects having each of the three operative procedures was evenly distributed between groups. As well, the number of subjects requiring narcotics or antimetics was comparable between groups. Therefore, the degree of narcotization would not affect the psychomotor and cognitive function test results when comparing the two populations. Our observations were also not affected by the addition of nitrous oxide or volatile anaesthetics.

The mean induction time was slightly extended (by

TABLE IV Psychomotor tests: comparison between groups

\begin{tabular}{lcc}
\hline & Propofol & Thiopentone \\
\hline $\begin{array}{l}\text { Deletion of P's (no. of P's missed) } \\
\quad\end{array}$ & \\
$\quad$ Baseline & $2.9 \pm 4.0$ & $5.2 \pm 6.2$ \\
$\quad$ Postoperative & $2.4 \pm 2.2$ & $4.4 \pm 3.6$ \\
$\begin{array}{l}\text { Trieger dot (no. of dots missed) } \\
\quad \text { Baseline }\end{array}$ & $2.5 \pm 2.5$ & $2.7 \pm 3.4$ \\
Postoperative & $6.0 \pm 6.4$ & $10.3 \pm 8.0^{*}$ \\
\hline
\end{tabular}

${ }^{*} P<0.05$ vs propofol.

TABLE III Recovery times

\begin{tabular}{lccc}
\hline & Propofol & Thiopentone & $P$ \\
\hline Eye opening (min) & $6.4 \pm 4.3$ & $13.9 \pm 15.9$ & $<0.02$ \\
Response to verbal command (min) & $7.6 \pm 6.30$ & $15.4 \pm 16.6$ & $<0.02$ \\
Orientation (min) & $22.7 \pm 12.8$ & $36.2 \pm 23.1$ & $<0.01$ \\
Aldrete score 10 (min) & $34.0 \pm 22.0$ & $56.6 \pm 24.8$ & $<0.001$ \\
Tolerate fluids (min) & $24.1 \pm 24.0$ & $25.1 \pm 32.3$ & $\mathrm{NS}$ \\
Sit independantly (min) & $44.9 \pm 22.8$ & $41.1 \pm 30.7$ & $\mathrm{NS}$ \\
Ability to walk at discharge (no. of patients) & 19 & 8 & $<0.01$ \\
Postoperative narcotics administered (number of patients) & $15 / 30$ & $14 / 30$ & $\mathrm{NS}$ \\
Postoperative IM gravol administered (number of patients) & $5 / 30$ & $4 / 30$ & $\mathrm{NS}$ \\
\hline
\end{tabular}




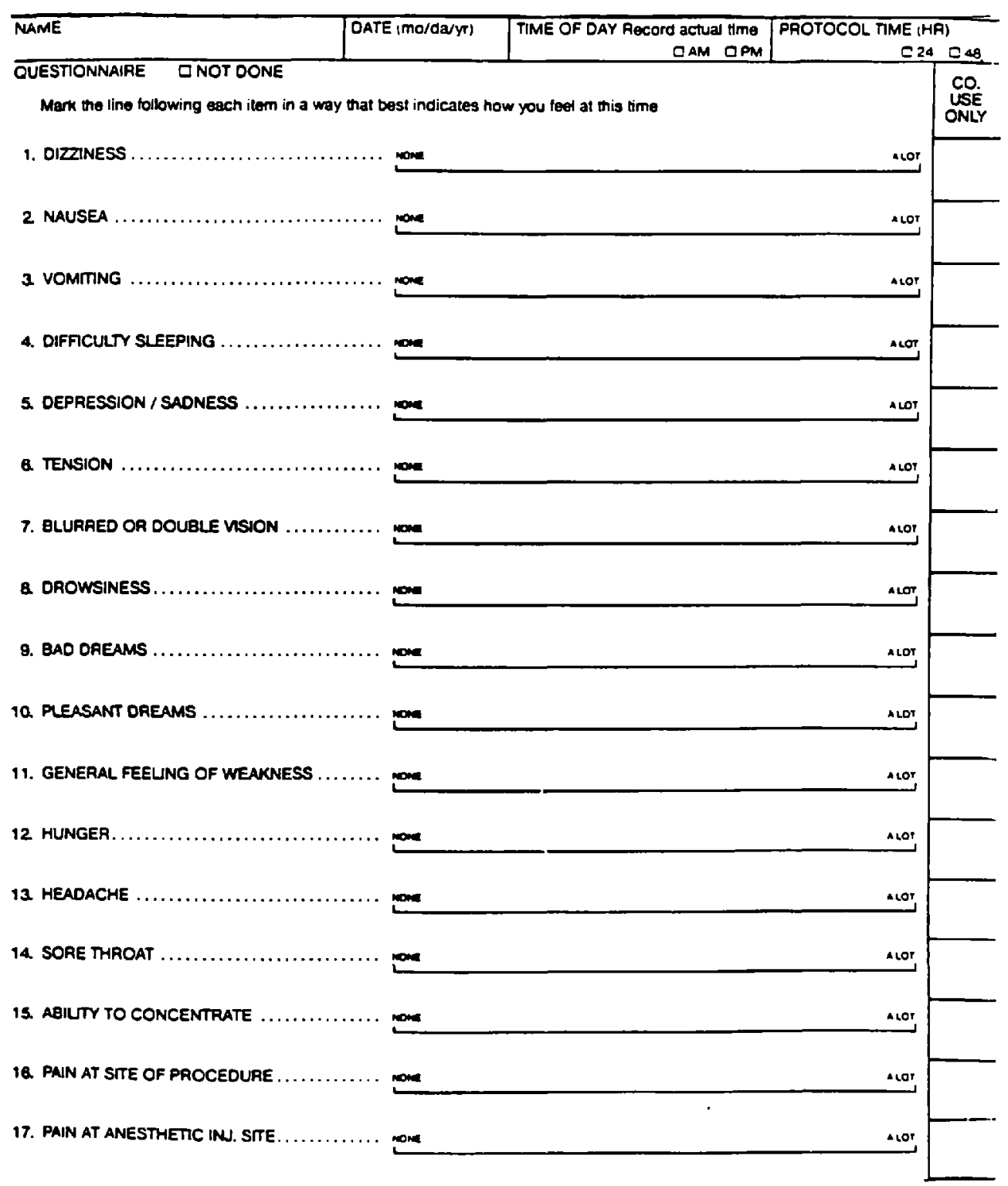

FIGURE 3 Visual analogue scale of adverse symptom

about 40 per cent or $12 \mathrm{sec}$ ); however, inductions were still both rapid and smooth with propofol. Although succinylcholine was administered after the loss of lid reflex, no excitatory side effects were noted with either drug until this point. ${ }^{10,11}$ Pain or discomfort on injection was more common with propofol but was never severe enough to necessitate the discontinuation of injection. A previous study by Briggs showed that the incidence of pain is diminished when the intravenous catheter is placed in a large vein. ${ }^{15}$

The cardiorespiratory effects of propofol have been compared with other intravenous agents in several studies. Grounds $e t$ al. in two separate articles noted that after the injection of propofol, compared with an equipotent dose of thiopentone, there was a significantly greater reduction in mean arterial blood pressure and systemic vascular resistance. ${ }^{16.17}$ Other research has confirmed these results as well as the absence of an increased heart rate with propofol. ${ }^{12,18-20}$ The present study showed that the tachycardic response to laryngoscopy, intubation and surgical stimulation was more effectively attenuated with propofol. The only significant difference in blood pressure between the two groups was a diminished elevation of both systolic and diastolic pressure post-intubation seen with propofol. Prys-Roberts ${ }^{21}$ and Grounds ${ }^{17}$ have both suggested that propofol resets the baroreceptor 
response to blood pressure changes. As well, there may be a greater depression of the cardiovascular system than with other IV agents. ${ }^{19.22}$ Although there are no specific analgesic properties ascribed to propofol, it produced a greater degree of reflex depression than an equipotent dose of thiopentone in mice. ${ }^{7}$ Despite several theories, the exact mechanisms which explain the haemodynamic effects of propofol have not yet been completely elucidated.

The dosages required for maintenance of anaesthesia were consistent with other studies. ${ }^{10,23-24}$ Supplemental boluses were required to treat light anaesthesia in 20 per cent of patients administered propofol. In no case were more than two boluses necessary during the entire surgical procedure. One subject given thiopentone indicated the presence of awareness for a short time at the beginning of a laparoscopy prior to trochar insertion. She could recall the conversation but stated that no pain was felt nor was she distressed by the experience.

Like others, we found recovery times of all measured variables to be more rapid with propofol. ${ }^{1,8}$ Patients opened their eyes and responded to verbal command in approximately half the time of the thiopentone group. Orientation to name, place and date of birth was also attained earlier. Psychomotor and cognitive function testing was performed every $30 \mathrm{~min}$ until PARR discharge only after the patient was able to sit independently. In most cases this occurred approximately $40 \mathrm{~min}$ after discontinuation of the infusion. In view of the fact that the average length of stay in the PARR was $60-90 \mathrm{~min}$, these tests were performed only once postoperatively. The ability to delete P's had returned to baseline, in both groups, as opposed to the Trieger test prior to transfer to the ward. Even though the Trieger dot test, a valid and reliable assessment of perceptual motor ability, ${ }^{25}$ had not completely returned to baseline, there was a significantly improved performance in the propofol group. It is important to note that on emergence most subjects receiving thiopentone complained of blurred vision which may have impaired their ability to focus properly on the test paper. More patients given propofol were able to pass the Romberg test and walk independently. All patients stay a minumum of $60 \mathrm{~min}$ in our recovery room prior to discharge, thus the relatively small difference in PARR discharge times did not accurately reflect the overall faster recovery times in the propofol group. We believe that the earlier cognitive and psychomotor function recovery after the use of propofol is of clinical importance.

The majority of subjects in both groups were satisfied with their anaesthetic. The major complaints of the four dissatisfied thiopentone patients were of postoperative nausea, vomiting and "hangover." The rapid return of consciousness with propofol was responsible for the two unsatisfied subjects, both of whom had undergone laser laryngoscopy. After the simultaneous discontinuation of both propofol and succinylcholine infusions, awakening occurred earlier than return of muscle strength, thus leaving an awake, partially paralyzed patient. Therefore one should ensure the return of adequate motor function prior to discontinuing the propofol infusion. By $24 \mathrm{hr}$ post-surgery, there was no significant difference in adverse symptoms ${ }^{26}$ between groups.

In conclusion, propofol is a safe anaesthetic drug. Total intravenous anaesthesia is easily induced and maintained by infusion with few intraoperative problems. The return of psychomotor performance and cognitive function and recovery times are more rapid after the administration of propofol than thiopentone. As well, fewer side effects are observed on emergence from anaesthesia. At $24 \mathrm{hr}$, there is no distinguishable difference between drugs, except a slightly greater subjective ability to concentrate following propofol. Therefore, propofol has the potential for early patient discharge and street fitness after outpatient procedures.

\section{References}

1 Edelist $G$. A comparison of propofol and thiopentone as induction agents in outpatient surgery. Can Anaesth Soc J 1987; 34: 110-6.

2 MacKenzie N, Grant IS. Comparison of the new emulsion formulation of propofol with methohexitone and thiopentone for induction of ancsthesia in day cases. $\mathrm{Br} \mathbf{J}$ Anaesth 1985; 57: 725-31.

3 Wells JKG. Comparison of ICI 35868, etomidate and methohexitone for day care anaesthesia. Br J Anaesth 1985; 57: 732-5.

4 Adam HK, Briggs LP, Bahar M, Douglas EJ, Dundee $J W$. Pharmacokinetic evaluation of ICI 35868 in man. Br J Anaesth 1983; 55, 97-103.

5 Schuttler J, Stoeckel $H$, Schwilden $H$. Pharmacokinetic and pharmacodynamic modelling of propofol (Diprivan) in volunteers and surgical patients. Postgrad Med J 1985; 61(supp 3): 53-4.

6 Glen JB, Hunter SC. Pharmacology of an emulsion formulation of ICl 35868. Br J Anaesth 1984; 56: 617-25.

7 Glen JB. Animal studics of the anaesthetic activity of $\mathrm{ICI}$ 35868. Br J Anaesth 1980; 52: 731-42.

8 Redern N, Stafford MA, Hull PF. Incremental propofol for short procedures. Br J Anaesth 1985; 57: 1178-82.

9 Doze VA, Shafer A, White PF. Propofol-nitrous oxide versus thiopental-isoflurane-nitrous oxide for general anesthesia. Anesthesiology 1988; 69: 63-71.

10 Kay $N H$, Uppingtion I, Sear $J W$, Allen $M C$. Use of an emulsion of ICI 35868 (propofol) for the induction and 
maintenance of anaesthesia. Br J Anaesth 1985; 57:

736-42.

11 Fragen RJ, Hanssen CHJH, Denissen AF, Booij Hoj, Crul $J B$. Diisoprofol (ICI 35868) for total intravenous anaesthesia. Acta Anaesthesiol Scand 1983; 27: 113-6.

12 Jessop E, Grounds RM, Morgan M, Lumley J. Comparison of infusions of propofol and methohexitone to provide light anaesthesia during surgery with regional blocks. Br J Anaesth 1985; 57: 1173-7.

13 Mouton SM, Bullington J, Davis L, Fisher K, Ramsey S, Wood $M$. A comparison of diprivan and thiopental for the induction of anesthesia. Anesthesiology 1985; 63: A354.

14 Plosker H, Sampson I, Cohen M, Kaplan JA. A comparison of diprivan and thiamylal sodium for the induction and maintenance of outpatient anesthesia. Anesthesiology 1985; 63: A366.

15 Briggs LP, Clarke RSJ, Dundee JW, Moore J, Bahar M, Wright $P J$. Use of di-isopropyl phenol as main agent for short procedures. Br J Anaesth 1981; 53: 1197-202.

16 Grounds RM, Morgan M, Lumsley J. Some studies on the propertics of the intravenous anaesthetic propofol (Diprivan): a review. Postgrad Med J 1985; 61 (suppl. 3): 9095.

17 Grounds RM, Twigley AJ, Carli F, Whitwam JG, Morgan $M$. The haemodynamic effects of intravenous infusion - comparison of the effects of thiopentone and propofol. Anaesthesia 1985; 40: 735-40.

18 Aun C, Major $E$. The cardiorespiratory effect of ICI 35868 in patients with valvular heart disease. Anaesthesia 1984; 39: 1096-100.

$19 O^{\prime}$ Callaghan AC, Normandale JP, Grundy EH, Lumley J, Morgan $M$. Continuous intravenous infusion of disoprofol (ICI 35868, Diprivan). Comparison with althesin to cover surgery under local anaesthesia. Anaesthesia 1982; 37: 295-300.

20 Cumming GC, Dixon J, Kay NH et al. Dose requirement of ICI 35868 (propofol, 'Diprivan') in a new formulation for induction of anaesthesia. Anaesthesia 1984; 39 : 1168-71.

21 Prys-Roberts $C$. Haemodynamic effects of 'Diprivan' infusion anaesthesia; comparison with other intravenous and volatile anaesthetics. VII European Congress of Anaesthesiology Abstracts III; 1986; 296.

22 Prys-Roberts C, Davies JR, Calverley RK, Goodman $N W$. Haemodynamic effects of infusion of diisopropylphenol (ICI 35868) during nitrous oxide anaesthesia in man. Br J Anaesth 1983; 55: 105-11.

23 Spelina KR, Coates DR, Monk CR, Prys-Roberts C, Norley I, Turtle $M J$. Dose requirements of propofol by infusion during nitrous oxide anaesthesia in man. $\mathrm{Br} \mathrm{J}$ Anaesth 1986; 56: 1080-4.
24 deGrood PMRM, Ruys AHC, van Egmond J, Borg Booij LHDJ, Crul JF. Propofol ('Diprivan') emulsion of total intravenous anaesthesia. Postgrad Med J 1985; 61 (suppl. 3): 61-9.

25 Letourneau JE, Denis $R$. The reliability and validity of the Treiger dot test as a measure of recovery from general anaesthesia in a day care surgical unit. Anaesthesia Progress 1983: September/October: 152-5.

26 Morrison DP. The crichton visual analogue scale for the assessment of behaviour in the elderly. Acta Psychiatr Scand 1983; 68: 408-13. 